\title{
Esophageal motility after laparoscopic sleeve gastrectomy
}

\author{
Eleni Sioka' \\ George Tzovaras' \\ Fotios Tsiopoulos ${ }^{2}$ \\ Dimitris Papamargaritis ${ }^{\prime}$ \\ Spyros Potamianos ${ }^{2}$ \\ Constantine Chatzitheofilou' \\ Dimitris Zacharoulis' \\ 'Department of Surgery, ${ }^{2}$ Department \\ of Gastroenterology, University \\ Hospital of Larissa, University of \\ Thessaly, Larissa, Greece
}

This article was published in the following Dove Press journal:

Clinical and Experimental Gastroenterology

20 July 2017

Number of times this article has been viewed

Background: Laparoscopic sleeve gastrectomy (LSG) modifies the upper gastrointestinal tract motility. Controversial data currently exist. The aim of the study was to evaluate esophageal motility before and after LSG.

Patients and methods: Morbid obese patients scheduled for LSG underwent reflux symptoms evaluation and manometry preoperatively and postoperatively. The preoperative and postoperative results were compared and analyzed.

Results: Eighteen patients were enrolled. Heartburn and regurgitation improved in $38.9 \%$ and $11.1 \%$ of the patients, but deteriorated in $11.1 \%$ and $27.8 \%$ of the patients, respectively. Lower esophageal sphincter (LES) total length decreased postoperatively ( $p=0.002$ ). Resting and residual pressures tended to decrease postoperatively (mean difference [95\% confidence interval]: $-4[-8.3 / 0.2] \mathrm{mmHg}, p=0.060 ;-1.4[-3 / 0.1] \mathrm{mmHg}, p=0.071$, respectively). Amplitude pressure decreased from $95.7 \pm 37.3$ to $69.8 \pm 26.3 \mathrm{mmHg}$ at the upper border of LES ( $p=0.014)$, and tended to decrease at the distal esophagus from $128.5 \pm 30.1$ to $112.1 \pm 35.4 \mathrm{mmHg}$ ( $p=0.06)$ and mid-esophagus from $72.7 \pm 34.5$ to $49.4 \pm 16.7 \mathrm{mmHg}(p=0.006)$. Peristaltic normal swallow percentage increased from $47.2 \pm 36.8$ to $82.8 \pm 28 \%(p=0.003)$. Postoperative regurgitation was strongly negatively correlated with LES total length (Spearman's $r=-0.670$ ). When groups were compared according to heartburn status, statistical significance was observed between the groups of improvement and deterioration regarding postoperative residual pressure and postoperative relaxation ( $p<0.002, p<0.002$, respectively). With regard to regurgitation status, there was statistically significant difference between groups regarding preoperative amplitude pressure at the upper border of LES $(p<0.056)$.

Conclusion: Patients developed decreased LES length and weakened LES pressure after LSG. Esophageal body peristalsis was also affected in terms of decreased amplitude pressure, especially at the upper border of LES. Nevertheless, body peristalsis was normalized postoperatively. LSG might not deteriorate heartburn. Regurgitation might increase following LSG due to shortening of LES length, particularly in patients with range of preoperative amplitude pressure at the upper border of LES of 38.9-92.6 mmHg.

Keywords: laparoscopic sleeve gastrectomy, motility, esophagus, manometry, gastro esophageal reflux, obesity surgery

\section{Introduction}

Laparoscopic sleeve gastrectomy (LSG) is an effective procedure for the treatment of morbid obesity. The technical ease of the technique has increased its popularity among surgeons and patients. LSG includes dissection of the stomach at a distance varying from 2 to $6 \mathrm{~cm}$ from the pylorus to the gastroesophageal junction in order to remove 
the largest part of the stomach and, especially, the fundus. Thus, LSG creates a gastric tube along the lesser curvature.

These anatomic alterations are anticipated to affect the physiology and motor function of the upper gastrointestinal tract. Specifically, the sleeve is distinguished in two functionally different sections: a mainly passive sleeve and an accelerated antrum. ${ }^{1}$ The sleeve is characterized by low distensibility and high intraluminal pressure. ${ }^{2}$ These parameters may aggravate the gastroesophageal reflux. By contrast, increased intragastric pressure may accelerate gastric emptying and in turn ameliorate any reflux. ${ }^{3} \mathrm{~A}$ recent systematic review of the effects of LSG in gastroesophageal reflux disease (GERD) showed conflicting results and mentioned a multifactorial correlation between GERD and LSG. ${ }^{4}$ Thus, patients after LSG may develop symptoms that require further physiological assessments.

Even though there is evidence that LSG affects gastric motility, ${ }^{5,6}$ there is a paucity of data regarding the postoperative esophageal motility. ${ }^{3}$ Manometry provides a measurable tool to monitor the esophageal motility alterations.

The aim of this prospective study was to evaluate the esophageal motility alterations following LSG. The correlation of manometric findings with reflux symptoms was also examined, aiming to determine whether the motility parameters replicated the symptoms.

\section{Patients and methods}

Patients who underwent to LSG at University Hospital of Larissa were enrolled in this prospective study. The Institutional Review Board of the University Hospital of Larissa approved this study. The patients provided written informed consent to participate in this research.

The inclusion criteria for surgery were set according to the 1991 NIH consensus criteria for bariatric surgery. ${ }^{7}$ The exclusion criteria for surgery included sweeters, patients with severe psychiatric disorders, drug addicts, alcoholics and patients with a high operative risk. Sweeter described individuals who consume sweets or sugar-added liquids more than $150 \mathrm{kcal}$ per portion at least three times per week. ${ }^{8}$

During the preoperative evaluation, an upper gastrointestinal endoscopy was performed. The esophagitis severity was graded according to the Los Angeles classification. ${ }^{9}$ The surgical technique was the same for all the patients and has been previously described in detail. ${ }^{10}$ Briefly, under the guidance of a $36 \mathrm{~F}$ bougie, a sleeve was created. The dissection started $5 \mathrm{~cm}$ from the pylorus. Preoperative and postoperative use of proton pump inhibitors was not indicated.
Patients were evaluated for reflux symptoms preoperatively and postoperatively using a reflux symptom assessment questionnaire, validated to the native language, as previously reported. ${ }^{11}$ Heartburn, regurgitation and vomiting symptoms were classified according to a grading scale (Figure S1).

Esophageal manometry was performed preoperatively and postoperatively using eight-channel water-perfused system that was introduced transnasally and positioned intragastrically with the patient in the supine position after 8 hours of fasting. Any medications with possible effects on esophageal motility were discontinued 5 days prior to the manometry. The manometry data were recorded using the POLYGRAM NET ${ }^{\mathrm{TM}}$ (Medtronic A/S, Copenhagen, Denmark) esophageal manometry application. The data were reviewed, and measures were collected from the data files for statistical analyses.

The lower esophageal sphincter (LES) was located using a stationary pull-through technique with the patient in the supine position. Esophageal body peristalsis was evaluated with 10 consecutive wet swallows of a $5 \mathrm{~mL}$ bolus of water at room temperature, which was separated by 30 -second intervals with the patient in the supine position. The esophageal contractions were analyzed for amplitude pressure, onset velocity, peak velocity, time propagation and duration at the upper border LES, distal esophagus and mid-esophagus. The esophageal contraction progression was classified into two types: peristaltic normal and abnormal. Esophageal contractions that showed a continuous progression down to the lower esophagus were considered as normal. Normal peristalsis was defined as esophageal contraction exhibiting amplitudes $>30 \mathrm{mmHg}$ at recording sites positioned 3 and $8 \mathrm{~cm}$ above LES. $^{12}$

The upper esophageal sphincter (UES) was also studied qualitatively, and the coordination between pharyngeal contractions and cricopharyngeal UES relaxation was assessed.

The preoperative and postoperative reflux symptoms were correlated with the manometric findings. The patients were divided into groups according to reflux status (improvement, deterioration and consistency).

\section{Statistical analysis}

The data were expressed as numbers, mean values, standard deviations, medians and interquartile ranges. Frequencies and percentages were used for categorical data. A normality test was performed using Shapiro-Wilk test and normal probability plots.

Changes in symptoms were examined using the paired $t$-test or Wilcoxon test in case of normality violations or 
ordinal data. The reflux symptoms were correlated with the manometric findings using Spearman's rank correlation (Spearman's $r$ ). Comparisons between groups with regard to reflux symptoms status were performed using analysis of variance with post hoc Bonferroni corrections as an adjustment for multiple comparisons.

All statistical analyses were performed with the SPSS statistical package, version 16.0.0 (SPSS Inc, Chicago, IL, USA). All tests were two-sided. A $p$-value $<0.05$ was considered as statistically significant.

\section{Results}

Eighteen patients were included in the study. Ten of them were women, and eight were men. The mean age was $40.7 \pm 8.1$ years (range 30-56 years). The mean preoperative body mass index (BMI) was $46.3 \pm 5.6 \mathrm{~kg} / \mathrm{m}^{2}$ (range $38-58 \mathrm{~kg} / \mathrm{m}^{2}$ ). The mean postoperative BMI was $31.1 \pm 4.3 \mathrm{~kg} / \mathrm{m}^{2}$ (range $24-40 \mathrm{~kg} / \mathrm{m}^{2}$ ). BMI reduced significantly postoperatively $(p<0.0005)$. The patients were evaluated preoperatively and at median interval of 7 months (6-15 months) postoperatively. Regarding complications, the treatment of one patient was converted to an open laparotomy due to bleeding.

\section{Gastroscopic findings}

The gastroscopic preoperative evaluation findings are reported in Table 1.

\section{Reflux symptoms}

Alterations in reflux symptoms were evaluated. Heartburn symptoms improved in seven patients (38.9\%), nine patients had no changes (50\%) and symptoms deteriorated in two patients (11.1\%). Regurgitation improved in two patients (11.1\%), 11 patients had no changes $(61.1 \%)$ and regurgitation worsened in five patients $(27.8 \%)$. No patient experienced vomiting (Figure 1).

\section{Manometric findings}

Coordination between pharyngeal contraction and UES relaxation was observed in all patients.

Table I Gastroscopic preoperative evaluation

\begin{tabular}{ll}
\hline Gastroscopic findings & Patients, $\mathbf{n}(\%)$ \\
\hline Normal & $6(33.3)$ \\
Esophagitis A & $2(11.1)$ \\
Esophagitis A-gastritis-duodenitis & $2(11.1)$ \\
Esophagitis B-gastritis & $1(5.5)$ \\
Esophagitis B-gastritis-duodenitis & $1(5.5)$ \\
Gastritis & $5(27.8)$ \\
Gastritis-duodenitis & $\mathrm{I}(5.5)$ \\
\hline
\end{tabular}

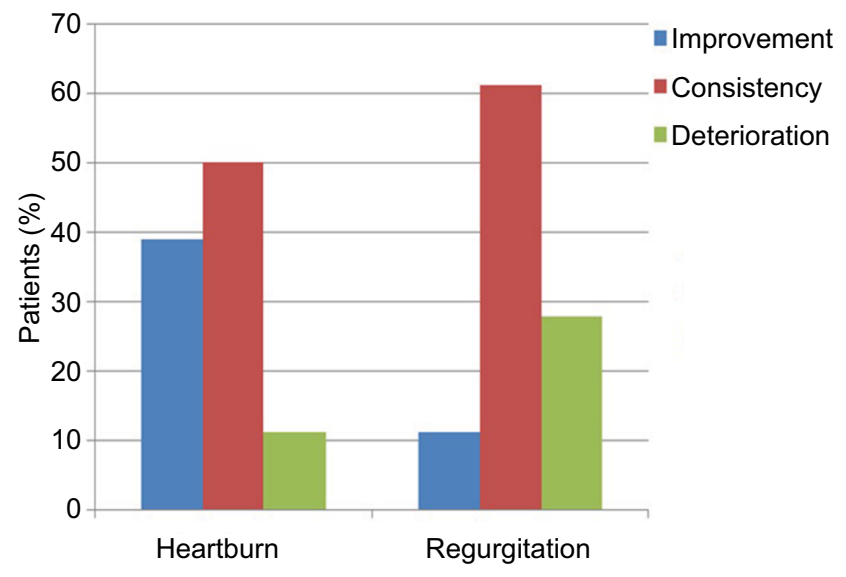

Figure I Reflux symptom evaluation.

\section{LES manometric data}

The LES total length was reduced in 13 patients (72\%) but remained unaffected in five patients (28\%) postoperatively. A decrease in the total LES length proved to be statistically significant after LSG $(p=0.002)$. There was a trend toward decreased resting pressures ([mean difference, 95\% confidence interval, $\mathrm{CI}]-4 \mathrm{mmHg}[-8.3 / 0.2], p=0.060)$ and residual pressures ([mean difference, $95 \% \mathrm{CI}]-1.4 \mathrm{mmHg}$ $[-3 / 0.1], p=0.071)$. In contrast, the relaxation percentage (\%) increased from $78.6 \pm 7.8$ to $84.8 \pm 10.6$ postoperatively without reaching statistical significance (Figure 2).

\section{The esophagus body manometric data}

The amplitude pressure decreased significantly from $95.7 \pm 37.3$ to $69.8 \pm 26.3 \mathrm{mmHg}$ at the upper border LES ([mean difference, 95\% CI] $-25.8 \mathrm{mmHg}[-45.7 /-6]$, $p=0.014$ ), while it tended to decrease in the distal esophagus from $128.5 \pm 30.1$ to $112.1 \pm 35.4 \mathrm{mmHg}$ ([mean difference, 95\% CI] $-16.3 \mathrm{mmHg}[-33.4 / 0.8], p=0.060)$ and in the mid-esophagus from $72.7 \pm 34.5$ to $49.4 \pm 16.7 \mathrm{mmHg}$ ([mean difference, $95 \% \mathrm{CI}]-23.4 \mathrm{mmHg}[-38.9 /-7.8], p=0.006$ ) (Figure 3).

Preoperatively, no patient fell under the category of ineffective esophageal motility. The majority of preoperative peristaltic abnormalities were hypertensive contractions. Furthermore, the peristaltic normal swallow percentage increased significantly from $47.2 \pm 36.8$ to $82.8 \pm 28$ ([mean difference, $95 \% \mathrm{CI}]+35.6[13.9 / 57.1], p=0.003$ ) (Figure 4).

\section{Correlations between the reflux symptoms and manometric findings}

The absolute reflux changes were correlated with the manometric findings and are presented in descending order in Table 2. 

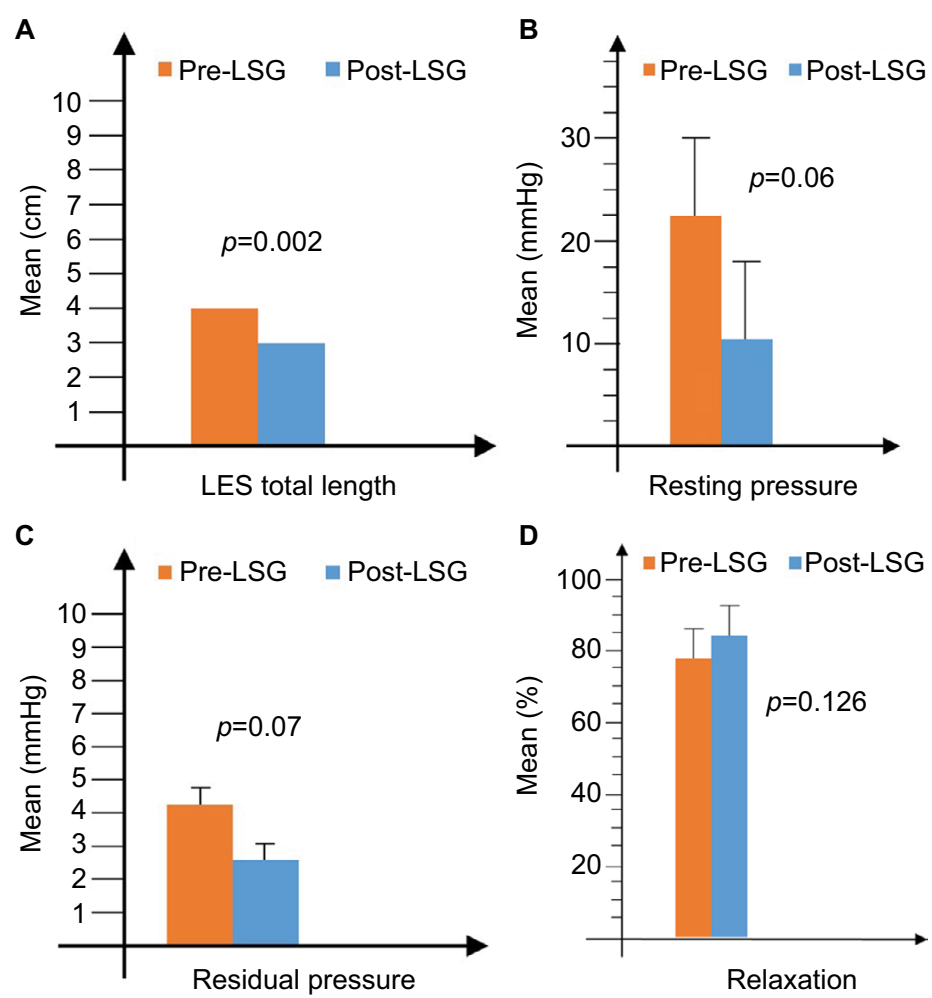

Figure 2 Manometric LES data: (A) LES total length, (B) resting pressure, (C) residual pressure, and (D) relaxation (\%).

Abbreviations: LES, lower esophageal sphincter; LSG, laparoscopic sleeve gastrectomy.

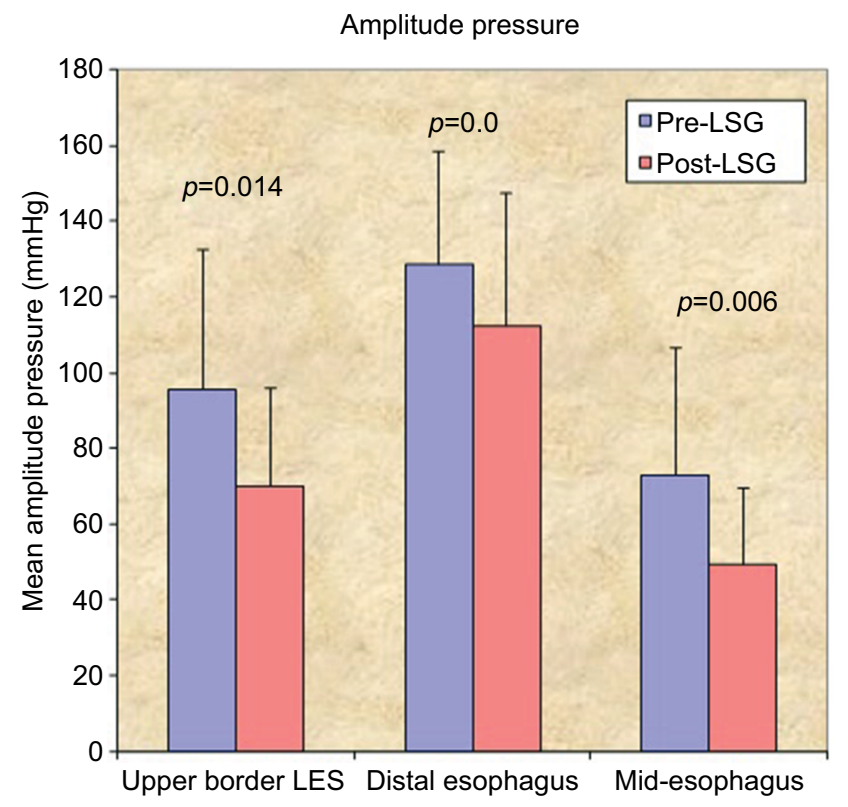

Figure 3 Amplitude pressure at the upper border LES, distal esophagus and midesophagus.

Abbreviations: LES, lower esophageal sphincter; LSG, laparoscopic sleeve gastrectomy.

The postoperative reflux symptom values were correlated with the manometric findings to determine if these parameters reflected the presented symptoms. Postoperative heartburn was significantly correlated with the mid-esophagus duration

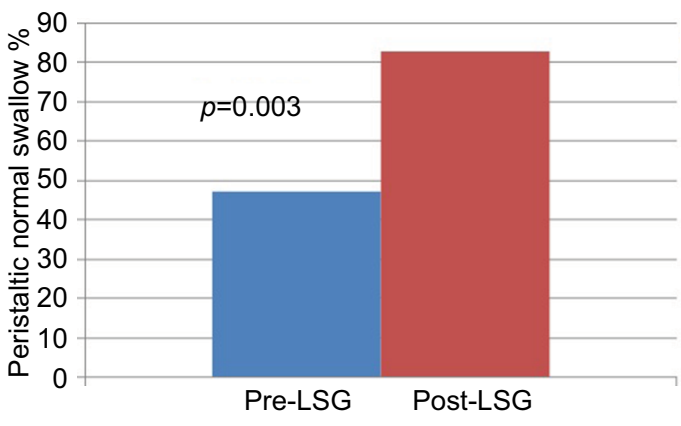

Figure 4 Peristaltic swallow modifications.

Abbreviation: LSG, laparoscopic sleeve gastrectomy.

(Spearman's $r=0.415, p=0.087$ ). The postoperative regurgitation was strongly negatively correlated with the total LES length (Spearman's $r=-0.670, p=0.002$ ) and the upper border LES peak velocity (Spearman's $r=-0.494, p=0.037$ ). Additionally, it was positively correlated with the resting pressure (Spearman's $r=0.532, p=0.023$ ), the distal esophagus propagation time (Spearman's $r=0.489, p=0.039$ ) and the mid-esophagus duration (Spearman's $r=0.454, p=0.059$ ).

When groups were compared according to heartburn status, statistical significance was observed between the groups of improvement and deterioration regarding postoperative residual pressure and postoperative relaxation $(p<0.002$, 
Table 2 Correlation of absolute changes of heartburn and regurgitation symptoms with the manometric findings

\begin{tabular}{|c|c|c|c|c|c|c|}
\hline & Positive correlation & Spearman's $r$ & p-value & Negative correlation & Spearman's $r$ & p-value \\
\hline \multirow[t]{3}{*}{ Heartburn } & Mid-esophagus onset velocity & 0.462 & 0.13 & Relaxation (\%) & -0.563 & 0.015 \\
\hline & Residual pressure & 0.363 & 0.139 & Mid-esophagus peak velocity & -0.434 & 0.159 \\
\hline & Upper border LES peak velocity & 0.355 & 0.161 & & & \\
\hline \multirow[t]{6}{*}{ Regurgitation } & Duration of distal esophagus & 0.467 & 0.051 & Relaxation (\%) & -0.414 & 0.088 \\
\hline & $\begin{array}{l}\text { Amplitude pressure of upper } \\
\text { border of LES }\end{array}$ & 0.463 & 0.053 & Onset velocity of mid-esophagus & -0.378 & 0.226 \\
\hline & Distal esophagus onset velocity & 0.429 & 0.086 & Peristaltic normal swallows (\%) & -0.351 & 0.153 \\
\hline & Residual pressure & 0.297 & 0.231 & Mid-esophagus peak velocity & -0.343 & 0.275 \\
\hline & $\begin{array}{l}\text { Amplitude pressure of } \\
\text { mid-esophagus }\end{array}$ & 0.280 & 0.260 & & & \\
\hline & $\begin{array}{l}\text { Propagation time of distal } \\
\text { esophagus }\end{array}$ & 0.257 & 0.303 & & & \\
\hline
\end{tabular}

Abbreviation: LES, lower esophageal sphincter.

$p<0.002$, respectively). With regard to regurgitation status, there was statistically significant difference between groups regarding preoperative amplitude pressure at the upper border of LES $(p<0.056)$.

\section{Discussion}

In the literature, there are no conclusive data for LSG outcomes regarding GERD symptoms because it still remains debatable whether GERD prevalence is increased or reduced after LSG. ${ }^{4,13,14}$ Furthermore, recent retrospective studies reported that patients experienced persistent GERD symptoms and new symptom onsets ranging from $8.6 \%$ to $20 \%$ after LSG. ${ }^{15-17}$ The proposed underlying pathophysiologic mechanisms that are responsible for the GERD symptoms are not adequately understood. Surgical technique parameters, such as blunting of the angle of His, presence of hiatal hernia, creation of a neofundus, final sleeve shape, alterations of hormone levels (decreased plasma ghrelin) and motility alterations (decreased gastric compliance and gastric emptying), are implicated in the increased GERD symptoms. In contrast, decreased abdominal obesity, accelerated gastric emptying, increased long-term gastric compliance, restoration of the angle of His, decreased acid production and decreased wall tension predispose patients to GERD symptom improvement. ${ }^{11,15,18}$

In this study, heartburn and regurgitation improved in $38.9 \%$ and $11.1 \%$ of the patients and deteriorated in $11.1 \%$ and $27.8 \%$ of the patients, respectively. New onset heartburn was defined in one patient (5.6\%), while new onset regurgitation was defined in four patients $(22.2 \%)$.

The aim of this prospective study was to evaluate the esophageal motility alterations following LSG. The authors showed that the resting pressure, residual pressure and LES total length were reduced postoperatively at a median interval of 7 months. Only two patients had hypotensive LES postoperatively, but these patients had no reflux symptoms. These results may be attributable to the fact that the increased intragastric pressure and the less distensible sleeve ${ }^{2}$ may provoke increased tension on the gastroesophageal wall junction, a reversely equivalent LES pressure decrease, increased relaxation and a parallel functional length decrease. These results are consistent with other series. ${ }^{19,20}$ The published data on esophageal motility are debatable. ${ }^{19-25}$ The variability in outcomes may be due to different postoperative evaluation timing or even variability in surgical techniques. Specifically, the postoperative follow-ups ranged from 6 days to 17 months. The bougie size varied from 32 to $40 \mathrm{~F}$. The dissections began from 2 to $3-4 \mathrm{~cm}$ from the pylorus in these studies. Thus, the created sleeve may have had different distensibility and intraluminal pressures and, in part, caused antrum preservation. In this study, the sleeve dissection began $5 \mathrm{~cm}$ from the pylorus using a 36F bougie. No patient had hiatal hernia.

Esophageal body peristalsis was also evaluated in the present study. Interestingly, the amplitude pressure was reduced at the upper border LES, distal and mid-esophagus after LSG, especially at the upper border LES. Postoperatively, also the authors showed that the time propagation and duration increased in all parts of esophagus, especially at the upper border LES. From the physical point of view, it is anticipated that when amplitude pressure decreased, time propagation and duration were increased compensating the weakened LES in order to create a new balance. It seems that esophagus is less distensible for longer periods of time following LSG. Whether the motility of esophagus is increased or reduced, it needs further evaluation with a gamma camera. The aforementioned alterations in parameters, such as amplitude pressure, time propagation and duration, might 
also create a new harmony in peristalsis and thus might also explain why the peristaltic normal swallow percentage increased after LSG. So far it is known that obesity is related to increased gastroesophageal pressure gradient leading to increased resistance to esophageal transit. Thus, obese patients present with hypercontractile pattern in the esophageal body. ${ }^{26}$ The improvement of the peristalsis after LSG might also be attributable to weight loss due to the abdominal pressure reduction. However, there is a paucity of data in the literature concerning the effect of weight loss on esophageal peristalsis. Further pathophysiological studies are needed to answer this issue.

The association between the manometric findings and the reflux symptoms was examined aiming to determine whether the motility parameters replicated the reflux symptoms. The strongest negative correlation was exhibited between the total LES length and postoperative regurgitation. Thus, the regurgitation deterioration may be correlated with a shortening of the total LES length. Focusing on the group of patients in which regurgitation deteriorated after LSG, we showed that preoperative amplitude pressure at the upper border of LES was statistically significantly different compared to the group in which regurgitation improved. Patients with improved regurgitation had high preoperative values at a mean of $172.8 \mathrm{mmHg}$, while patients with deteriorated regurgitation had lower mean values of $70.6 \mathrm{mmHg}$. It seems that regurgitation might increase following LSG due to shortening of LES length, particularly in patients with a range of preoperative amplitude pressure at the upper border of LES of 38.9-92.6 $\mathrm{mmHg}$.

Focusing on the group of patients in which heartburn deteriorated, there was no supportive data to predict patients with deterioration of heartburn preoperatively. According to this study, the sleeve was characterized by the motility pattern of decreased residual pressure and increased percentage relaxation, which is consistent with the clinically decreased heartburn postoperatively. By contrast, patients in whom heartburn deteriorated presented with increased residual pressure and reduced percentage relaxation postoperatively. Thus, it seems that LSG might not deteriorate heartburn.

Limitations of this study include a small sample size and the paucity of ph-metry in our institution. Patients felt uncomfortable with manometry and refused to undergo this difficult procedure. However, this was a prospective study that included objective clinical and physiological reflux symptom assessment. The data could be useful for a systematic review. Further studies are required in order to clarify the effects of sleeve gastrectomy on esophageal motility.

\section{Conclusion}

The patients developed decreased LES length and weakened LES pressure after LSG. Esophageal body peristalsis was also affected in terms of decreased amplitude pressures, especially at the upper border LES. Nevertheless, the body peristalsis was normalized. LSG might not deteriorate heartburn. Regurgitation might increase following LSG due to shortening of LES length, particularly in patients with a range of preoperative amplitude pressure at the upper border of LES of 38.9-92.6 $\mathrm{mmHg}$.

\section{Disclosure}

The authors report no conflicts of interest in this work.

\section{References}

1. Baumann T, Kuesters S, Grueneberger J, et al. Time-resolved MRI after ingestion of liquids reveals motility changes after laparoscopic sleeve gastrectomy-preliminary results. Obes Surg. 2011;21(1):95-101.

2. Yehoshua RT, Eidelman LA, Stein M, et al. Laparoscopic sleeve gastrectomy-volume and pressure assessment. Obes Surg. 2008;18(9):1083-1088.

3. Ardila-Hani A, Soffer EE. Review article: the impact of bariatric surgery on gastrointestinal motility. Aliment Pharmacol Ther. 2011; 34(8):825-831.

4. Chiu S, Birch DW, Shi X, Sharma AM, Karmali S. Effect of sleeve gastrectomy on gastroesophageal reflux disease: a systematic review. Surg Obes Relat Dis. 2011;7(4):510-515.

5. Melissas J, Leventi A, Klinaki I, et al. Alterations of global gastrointestinal motility after sleeve gastrectomy: a prospective study. Ann Surg. 2013;258(6):976-982.

6. Melissas J, Daskalakis M, Koukouraki S, et al. Sleeve gastrectomy-a "food limiting" operation. Obes Surg. 2008;18(10):1251-1256.

7. NIH conference. Gastrointestinal surgery for severe obesity. Consensus Development Conference Panel. Ann Intern Med. 1991;115(12): 956-961.

8. Brolin RE, Robertson LB, Kenler HA, Cody RP. Weight loss and dietary intake after vertical banded gastroplasty and Roux-en-Y gastric bypass. Ann Surg. 1994;220(6):782-790.

9. Lundell LR, Dent J, Bennett JR, et al. Endoscopic assessment of oesophagitis: clinical and functional correlates and further validation of the Los Angeles classification. Gut. 1999;45(2):172-180.

10. Zacharoulis D, Sioka E, Papamargaritis D, et al. Influence of the learning curve on safety and efficiency of laparoscopic sleeve gastrectomy. Obes Surg. 2012;22(3):411-415.

11. Lazoura O, Zacharoulis D, Triantafyllidis G, et al. Symptoms of gastroesophageal reflux following laparoscopic sleeve gastrectomy are related to the final shape of the sleeve as depicted by radiology. Obes Surg. 2011;21(3):295-299.

12. Spechler SJ, Castell DO. Classification of oesophageal motility abnormalities. Gut. 2001;49(1):145-151.

13. Tai CM, Huang CK. Increase in gastroesophageal reflux disease symptoms and erosive esophagitis 1 year after laparoscopic sleeve gastrectomy among obese adults. Surg Endosc. 2013;27(10):3937.

14. Daes J, Jimenez ME, Said N, Dennis R. Improvement of gastroesophageal reflux symptoms after standardized laparoscopic sleeve gastrectomy. Obes Surg. 2014;24(4):536-540.

15. Carter PR, LeBlanc KA, Hausmann MG, Kleinpeter KP, deBarros SN, Jones SM. Association between gastroesophageal reflux disease and laparoscopic sleeve gastrectomy. Surg Obes Relat Dis. 2011;7(5): 569-572.

16. Howard DD, Caban AM, Cendan JC, Ben-David K. Gastroesophageal reflux after sleeve gastrectomy in morbidly obese patients. Surg Obes Relat Dis. 2011;7(6):709-713. 
17. DuPree CE, Blair K, Steele SR, Martin MJ. Laparoscopic sleeve gastrectomy in patients with preexisting gastroesophageal reflux disease: a national analysis. JAMA Surg. 2014;149(4):328-334.

18. Laffin M, Chau J, Gill RS, Birch DW, Karmali S. Sleeve gastrectomy and gastroesophageal reflux disease. J Obes. 2013;2013:741097.

19. Braghetto I, Lanzarini E, Korn O, Valladares H, Molina JC, Henriquez A. Manometric changes of the lower esophageal sphincter after sleeve gastrectomy in obese patients. Obes Surg. 2010;20(3):357-362.

20. Burgerhart JS, Schotborgh CA, Schoon EJ, et al. Effect of sleeve gastrectomy on gastroesophageal reflux. Obes Surg. 2014;24(9): 1436-1441.

21. Gorodner V, Buxhoeveden R, Clemente G, Solé L, Caro L, Grigaites A. Does laparoscopic sleeve gastrectomy have any influence on gastroesophageal reflux disease? Preliminary results. Surg Endosc. 2015;29(7):1760-1768.
22. Moon RC, Teixeira AF, Jawad MA. Is preoperative manometry necessary for evaluating reflux symptoms in sleeve gastrectomy patients? Surg Obes Relat Dis. 2015;11(3):546-551.

23. Del Genio G, Tolone S, Limongelli P, et al. Sleeve gastrectomy and development of "de novo" gastroesophageal reflux. Obes Surg. 2014;24(1):71-77.

24. Petersen WV, Meile T, Küper MA, Zdichavsky M, Königsrainer A, Schneider JH. Functional importance of laparoscopic sleeve gastrectomy for the lower esophageal sphincter in patients with morbid obesity. Obes Surg. 2012;22(3):360-366.

25. Kleidi E, Theodorou D, Albanopoulos K, et al. The effect of laparoscopic sleeve gastrectomy on the antireflux mechanism: can it be minimized? Surg Endosc. 2013;27(12):4625-4630.

26. Fornari F, Callegari-Jacques SM, Dantas RO, Scarsi AL, Ruas LO, de Barros SG. Obese patients have stronger peristalsis and increased acid exposure in the esophagus. Dig Dis Sci. 2011;56(5):1420-1426. 


\title{
Supplementary Material
}

\author{
Heartburn \\ $0:$ no symptoms \\ 1: $<2$ episodes per week \\ 2: $>2$ episodes + proton pump inhibitors \\ 3: esophagitis grade >II (Los Angeles classification) \\ 4: complications (stenosis, ulcer, Barrett's esophagus) \\ Regurgitation \\ 0 : no symptoms \\ 1: $<2$ episodes per week \\ 2: $>2$ episodes per week, no medication \\ 3: $>2$ episodes per week + medications (i.e., prokinetics) \\ Vomiting \\ 0 : no symptoms \\ 1: $<2$ episodes per week \\ 2: > episodes per week
}

Figure SI Reflux symptoms assessment questionnaire

\section{Publish your work in this journal}

Clinical and Experimental Gastroenterology is an international, peerreviewed, open access, online journal publishing original research, reports, editorials, reviews and commentaries on all aspects of gastroenterology in the clinic and laboratory. This journal is included on PubMed. The manuscript management system is completely online and includes a very quick and fair peer-review system, which is all easy to use. Visit http://www.dovepress.com/testimonials.php to read real quotes from published authors.

Submit your manuscript here: https://www.dovepress.com/clinical-and-experimental-gastroenterology-journal 